\title{
JURISPRUDÊNCIA DEFENSIVA: RESTRIÇÃO AO DIREITO FUNDAMENTAL DE ACESSO À JUSTIÇA
}

\author{
Raquel Xavier Vieira Braga ${ }^{1}$
}

RESUMO: A quantidade avassaladora de processos que tramitam nos Tribunais levou o Poder Judiciário a adotar uma postura cada vez mais rígida com relação à admissibilidade dos recursos. A hipótese do presente artigo é verificar se os mecanismos de jurisprudência defensiva adotados pelos Tribunais brasileiros inviabilizam o acesso à justiça. Para tanto, será mapeada a jurisprudência defensiva, analisado o sistema de garantias processuais e verificada as consequências da restrição ao acesso à justiça. Finalmente, será constatado que o direito fundamental à justiça não pode ser sacrificado em nome da diminuição do congestionamento de processos no Poder Judiciário.

PALAVRAS-CHAVE: Jurisprudência; recursos; admissibilidade; acesso à justiça.

\section{DEFENSIVE JURISPRUDENCE: RESTRICTION TO THE FUNDAMENTAL RIGHT OF ACCESS TO JUSTICE}

ABSTRACT: The overwhelming amount of lawsuits that are being processed in the Courts led the Judiciary to adopt an increasingly rigid stance regarding the admissibility of appeals. The hypothesis of this article is to verify whether the defensive jurisprudence mechanisms adopted by the Brazilian Courts make access to justice unfeasible. To this end, defensive jurisprudence will be mapped and the system of procedural guarantees and the effects of restrictions on access to justice will be analyzed. Finally, it will be noted that the fundamental right to justice cannot be sacrificed in the name of diminishing cases in the Judiciary.

KEYWORDS: Jurisprudence; resources; admissibility; access to justice.

\section{INTRODUÇÃO}

A sobrecarga de processos que tramitam no Poder Judiciário faz com que os Tribunais, notadamente os Superiores, criem, cada vez mais, obstáculos para a admissibilidade dos recursos. A frequente aplicação da jurisprudência defensiva, entendida

\footnotetext{
${ }^{1}$ A autora é mestra em direito pela Universidade Federal do Rio Grande do Sul (2013), especialista em Direito Tributário pela Fundação Getúlio Vargas (2003) e em Direito Empresarial pela Universidade Federal do Rio Grande do Sul (2009), possui graduação em Direito pela Universidade Católica de Pelotas (2001), é membro do Instituto de Estudos Tributários (IET) e da Comissão Nacional da Mulher Advogada, foi assessora jurídica de Ministra do Supremo Tribunal Federal (2014-2016), é doutoranda em Direito no Centro Universitário de Brasília (UniCEUB) e advogada em Brasília.

* Endereço eletrônico: raquelxb07@gmail.com. Endereço postal: SQSW 303 Bloco D apartamento 211, CEP 70673-304, Sudoeste, Brasília/DF.
} 
como as decisões judiciais que não conhecem questões jurídicas, pela justificativa de não preenchimento dos requisitos formais para apreciação do mérito dos recursos, é um fenômeno contínuo e crescente que integra e compõe a realidade processual brasileira.

$\mathrm{O}$ direito fundamental à justiça pode ser sacrificado em nome da tentativa de diminuição do congestionamento de processos no Poder Judiciário?

O presente artigo se propõe a investigar se a criação de obstáculos rígidos ao exame do mérito dos recursos pode se tornar um verdadeiro impedimento de acesso ao judiciário através da análise dos textos normativos, da doutrina e da investigação crítica das decisões dos Tribunais Superiores, permitindo uma distância segura com o objeto de estudo.

A Constituição Federal de 1988, em seu artigo $5^{\circ}, \mathrm{XXXV}$, garante a todos o direito ao mais amplo acesso à justiça porque é através dele que os demais direitos fundamentais podem ser efetivados. O ícone do sistema processual de garantias, assim como a materialização do Estado Democrático de Direito, é a existência de um Poder Judiciário acessível a todos.

A dificuldade aguda enfrentada pelo jurisdicionado que não consegue levar suas questões jurídicas em frente porque está diante de um poder judiciário assoberbado com a quantidade das demandas judiciais da sociedade brasileira é uma questão extremamente sensível que toca no sistema das garantias processuais. O interminável conflito entre a erosão do judiciário e a frustração do jurisdicionado revela a importância do presente estudo, justificando a sua elaboração.

Será examinado o congestionamento de processos nos órgãos judiciários e a forma como o Poder Judiciário está lidando com isso para, assim, mapear as tentativas de aprimoramento dos filtros recursais e, então, investigar se há compatibilidade entre a jurisprudência defensiva e o sistema de garantias processuais, através de uma análise detida do direito fundamental de acesso à justiça e do arquétipo do sistema de garantias processuais brasileiro, de modo a vislumbrar o efeito rebote da aplicação da jurisprudência defensiva: as inúmeras ações rescisórias.

\section{A JURISPRUDÊNCIA DEFENSIVA NO SUPERIOR TRIBUNAL DE JUSTIÇA E NO SUPREMO TRIBUNAL FEDERAL}




\subsection{O congestionamento dos órgãos judiciários}

A sociedade brasileira, movida por complexas forças econômicas, sociais, políticas, jurídicas e psíquicas, possui o perfil de litigar. Um dos relevantes efeitos deste sintoma comportamental é o congestionamento dos órgãos judiciários.

No Superior Tribunal de Justiça, por exemplo, segundo VAUGHN (2016: 344-345), os dados são alarmantes:

Atualmente, o Poder Judiciário brasileiro lida com mais de 105 milhões de processos. Desses, aproximadamente 300 mil encontram-se pendentes de julgamento no STJ, o que representa $0,3 \%$ do total de litígios judiciais que assombram o país.

Desde sua criação, em julho de 1989, até meados de 2015, o STJ recebeu 4.500.929 processos, com uma média de 166.701 processos por ano, e julgou 5.136.186, com uma média anual de 190.229 feitos, sendo 155.652 por Ministro - lembre-se que a composição da Corte é de 33 ministros, conforme o art. 104 da CF/1988.

Como se vê, é natural que o Poder Judiciário busque formas de lidar com estes números e adote mecanismos para diminuir o acervo dos processos. Segundo dados do relatório Justiça em Números, em 2019 tramitaram nos tribunais do Brasil 77,1 milhões de processos, com média de 2.107 processos baixados por magistrado, o índice de produtividade dos servidores do judiciário cresceu $14,1 \%$ e a taxa de congestionamento foi de $68,5 \%$, menor índice experimentado pelo Poder Judiciário (CNJ: 2020, 5).

Desse modo, a jurisprudência defensiva é utilizada para dar vazão ao congestionamento de processos nos Tribunais. Para tanto, as Cortes Superiores são extremamente exigentes e rigorosas com o jurisdicionado, não faltando justificativas para não admissão dos recursos. Assim, o preenchimento dos requisitos de cabimento dos recursos é tarefa cada vez mais difícil de cumprir.

O Supremo Tribunal Federal, por sua vez, reconhece que a jurisprudência defensiva pesa nos ombros da parte. O voto do Ministro GILMAR MENDES no julgamento do AI 496136 AgRg, de relatoria do Ministro Celso de Mello, ${ }^{2}$ não deixa dúvidas:

\footnotetext{
2 Julgado em 15/05/2004.
} 
É evidente que a orientação dominante está presidida por aquela denominada por alguns de nós de 'jurisprudência defensiva'. Cabe à parte, portanto, tomar todas as medidas para o recurso ser adequadamente aviado e chegue ao Tribunal em condições de ser devidamente apreciado.

A tendência de não admitir os recursos é uma realidade do Poder Judiciário.

Os filtros recursais são importantes, até mesmo para manter a dignidade dos Tribunais e respeitar suas competências, devidamente previstas na Constituição Federal de 1988, mas a inquietação surge quando, no afã de barrar os recursos, os Tribunais Superiores suprimem do jurisdicionado o acesso à justiça, direito fundamental garantido pelo artigo $5^{\circ}$, XXXV da Constituição, ou o restringem de modo intolerável.

\subsection{Principais mecanismos de jurisprudência defensiva}

As formas mais frequentes de jurisprudência defensiva são as súmulas, as multas processuais, a interpretação restritiva de dispositivos normativos e os precedentes jurisprudenciais.

Em relação às súmulas, há a famosa Súmula 7, do Superior Tribunal de Justiça, a qual prevê que "A pretensão de simples reexame de prova não enseja recurso especial." Contudo, o significado da expressão "reexame de prova" é de difícil constatação e implica diferenciar reexame de valoração jurídica da prova. Caso contrário, não haverá chance de o Recurso Especial ser conhecido. Ademais, o Superior Tribunal de Justiça, muitas vezes, aplica a Súmula n. 07 com acentuada discricionariedade, calibrando as dificuldades enfrentadas pelo jurisdicionado que bate na sua porta.

Ainda, a súmula 182 do Superior Tribunal de Justiça, recentemente criada, também é digna de destaque. Segundo ela, "o recorrente deve impugnar todos os fundamentos da decisão agravada."3 Desse modo, o recurso - agravo, no caso - deve mencionar, detalhadamente e de forma explícita, todos os fundamentos da decisão e impugnar cada um deles.

Na verdade, a exigência prevista nesta súmula não causa estranheza, mas o modo como o Superior Tribunal de Justiça a utiliza sim, pois não é raro a Corte aplicar referida

\footnotetext{
${ }^{3}$ Referida súmula adveio do julgamento, na Corte Especial, do EAREsp n. ${ }^{\text {o }} 746.775$ - PR, Relator Ministro João Otávio Noronha, R. P/ Acórdão Ministro Luis Felipe Salomão. Julgado em 19/07/2018.
} 
súmula nos casos de recursos interpostos antes da sua criação, em clara situação de insegurança jurídica para o jurisdicionado. Além do mais, referida aplicação retroativa provoca a interposição de mais recursos, de modo que, definitivamente, não resolve o problema.

Como se vê, não faltam entraves para os Tribunais Superiores evitarem a apreciação do mérito das questões apresentadas pelo jurisdicionado o que, em certa medida, provoca um círculo vicioso de efeito recursal em cascata.

Outra súmula muito utilizada pelas Cortes Superiores é a 284 do Supremo Tribunal Federal: "É inadmissível o recurso extraordinário, quando a deficiência na sua fundamentação não permitir a exata compreensão da controvérsia." Na verdade, essa súmula impõe um importante limite aos litigantes, exigindo a elaboração de um recurso claro, devidamente concatenado, com consistência e coerência. Contudo, se não for aplicada de maneira correta, pode obstaculizar o acesso à justiça quando, por exemplo, o jurisdicionado interpõe Agravo em face de uma decisão refratária sobre juízo de admissibilidade que dificultou as possibilidades de enfrentamento da matéria e sobre elas não se pronunciou satisfatoriamente, de modo a encurralar o jurisdicionado na questão da "deficiência".

Além disso, o recorrente esbarrará em outra barreira, como seria o caso da súmula 282, do Supremo Tribunal Federal, que assim dispõe: "É inadmissível o recurso extraordinário, quando não ventilada, na decisão recorrida, a questão federal suscitada", ou seja, além de não conseguir deixar clara a compreensão da controvérsia porque ela não foi enfrentada pela decisão recorrida, o jurisdicionado ainda encontra o impedimento de que a questão deveria ter sido ventilada na decisão recorrida, mas não foi.

Desse modo, a aglutinação das súmulas bloqueadoras de admissibilidade dos recursos impõe ao jurisdicionado um esforço praticamente inglório, pois suas chances, muitas vezes, são mínimas, mesmo nos casos em que a parte trata o processo com a seriedade esperada, em observância aos princípios da participação, colaboração e prevenção, previstos no artigo $6^{\circ}$ do Código de Processo Civil.

Além disso, dois exemplos, não previstos em lei, evidenciam a insegurança jurídica diante da aplicação da jurisprudência defensiva, pelos Tribunais Superiores, em detrimento das garantias processuais:

a) A instabilidade na definição das competências do Supremo Tribunal Federal e do Superior Tribunal de Justiça nos casos em que o Superior Tribunal de Justiça, ao analisar 
Recurso Especial, entende que a matéria é de estatura constitucional e, portanto, de competência do Supremo Tribunal Federal, que, por sua vez, decide que a matéria é infraconstitucional. $^{4}$

b) $\mathrm{O}$ apego demasiado pelo formalismo nas hipóteses de intempestividade do recurso diante da falta de comprovação prévia de feriado local. ${ }^{5}$

Assim, há uma indeterminação quanto à definição das competências do Supremo Tribunal Federal e do Superior Tribunal de Justiça e, também, um forte apreço ao formalismo, hipóteses em que o acesso à justiça é gravemente tolhido.

Outro bloqueio ao acesso ao judiciário está na imposição de multa processual pela oposição dos embargos de declaração que vem se tornando práxis nos Tribunais, não só os Superiores. Tal amedrontamento vem ocorrendo com vários jurisdicionados, tendo em vista que o Poder Judiciário está proferindo decisões impondo multa nos embargos de declaração opostos pelo jurisdicionado, como no julgamento do REsp 682.932/SP, em que a parte foi intimada para esclarecer se "insistia" no conhecimento dos seus embargos de declaração, ainda que utilizados pela primeira vez, e advertida sobre o cabimento da $\operatorname{multa}^{6}$ e no julgamento dos EDcl nos EDcl nos EDcl no REsp n. ${ }^{\circ}$ 839.473/DF, em que aplicada multa mesmo com a existência de voto vencido que reconhecia erro material e acolhia parcialmente os embargos de declaração. ${ }^{7}$ Como se vê, o jurisdicionado acaba sendo penalizado "com marteladas" e discriminado por lançar mão de instrumentos processuais que estariam, pelo Código de Processo Civil, à sua disposição quando as hipóteses da sua utilização ocorressem.

Não se olvida que abusos devem ser rechaçados, mas não se pode impedir o direito à jurisdição e nem permitir ameaças ao jurisdicionado, pois a aplicação automática da jurisprudência defensiva, sem fundamentação legítima, agride o espírito dos direitos fundamentais e viola o sistema de garantias processuais.

\footnotetext{
${ }^{4}$ Em matéria tributária, o STJ entendeu que na exclusão sumária do contribuinte do programa de parcelamento de dívidas (REFIS) a ofensa a princípios seria constitucional, e, portanto, de competência do STF.

Ocorre que o STF, sobre idêntica questão, concluiu tratar-se de matéria infraconstitucional.

Os julgados, respectivamente, são: STJ, AgRg no Ag n. ${ }^{\circ} 902614$ - PR, Relatora Ministra Denise Arruda, Dj 12/12/2007; STF, RE n. ${ }^{\circ} 551476$ AgR - DF, Relator Ministro Menezes de Direito, Dj 27/08/2009.

${ }^{5}$ STJ, AgInt no Agravo em Recurso Especial n. ${ }^{\circ}$ 957.821/MS. Corte Especial. Rel. Ministro Raul Araújo. Red. p/acórdão Ministra Nancy Andrighi, por maioria, julgado em 20/11/2017.

${ }^{6}$ Transcreve-se o despacho, proferido pelo STJ, em 19/04/2017, no julgamento do REsp n. ${ }^{\circ}$ 682.932/SP, de relatoria do Ministro Moura Ribeiro: "Para que se evite alegação de surpresa e considerando a aplicabilidade das normas do NCPC a este recurso, especialmente o cabimento de multa (art. 1.021, $4^{\circ}$, e 1.026 , $\S 2^{\circ}$, do NCPC), intime-se a parte recorrente a esclarecer se insiste no seu conhecimento. O silêncio será interpretado como desistência. Publique-se. Intimem-se."

${ }^{7}$ No caso em hipótese, o voto vencido foi do Ministro Napoleão Nunes Maia Filho.
} 
Ainda, outro mecanismo de óbice ao enfrentamento do mérito dos recursos é quando o jurisdicionado se insurge em face de matéria com entendimento que já foi consolidado pelos Tribunais por meio da criação de precedente jurisprudencial. ${ }^{8}$ Percebe-se que, mesmo nos casos em que há uma distinção digna de nota, a resistência dos Tribunais em constatar o distinguish é altíssima. Por outro lado, quando não é o caso de distinção, mas de superação da própria jurisprudência, em razão de um novo olhar ou de significativas mudanças no campo social, cultural, econômico ou político, muitas vezes se perde a possibilidade de avanços no direito devido à decisões apressadas que aplicam exigências formais para não adentrar no mérito ou, ainda que se consiga sensibilizar o Poder Judiciário para adotar percepções e interpretações progressistas, as partes vivenciam uma extrema insegurança quanto à possibilidade de modulação dos efeitos da decisão sem saber, caso ela venha a ser feita, em qual posição jurídica elas se encontrarão.

\subsection{Aprimoramento nos filtros recursais}

A doutrina brasileira, preocupada com a sobrecarga de processos nos Tribunais Superiores, lamenta que a Repercussão Feral, prevista para o Supremo Tribunal Federal, como tentativa de aprimoramento dos filtros recursais, não tenha sido implementada também para o Superior Tribunal de Justiça.

Conforme WAMBIER $(2007,368)$ :

Vejo com bons olhos a reintrodução no ordenamento jurídico brasileiro, mais especificadamente no sistema recursal, da figura da repercussão geral. Trata-se indubitavelmente de figura que tende a reconduzir o STF à sua verdadeira função, que é a de proferir decisões sobre o direito objetivo - no que diz respeito à sua eficácia, à sua inteireza e à uniformidade de sua interpretação - em matéria constitucional, quando os temas trazidos à discussão tenham relevância para a Nação.

(...)

Lamenta-se que não tenha sido adotado também para selecionarem-se os recursos especiais que vão para o STJ. O fato de só haver repercussão geral para os recursos extraordinários reflete, de certo modo, uma incongruência, já que se poderia pensar

\footnotetext{
${ }^{8}$ Como no caso das Súmulas n. ${ }^{\circ} 83$ e 568 do Superior Tribunal de Justiça.
} 
no que diz respeito a problemas ligados à Constituição Federal, deveriam ser selecionadas questões relevantes.

Contudo, é questionável se realmente o instituto da Repercussão Geral seria um transplante eficiente para o Superior Tribunal de Justiça, dada sua competência, autonomia e funcionamento.

Talvez o melhor caminho seja analisar a formatação dos Tribunais Superiores, ao invés de criar mais um filtro recursal que, se não aplicado com a devida cautela, pode agredir o sistema de garantias processuais.

Além da criação de filtros recursais, seu aprimoramento é também preocupação do legislador, como se vê no Código de Processo Civil de 2015, que prevê a valorização do princípio da primazia da resolução de mérito.

De acordo com o referido princípio, o enfrentamento do mérito não deve ser obstaculizado por questões formais que sejam superáveis.

Aduz CÂMARA $(2015,45)$ :

Por força desse princípio, combate-se a jurisprudência defensiva, sendo, portanto, equivocado identificar obstáculos superáveis (à resolução do mérito) e não envidar esforços para os superar. A decretação de uma nulidade, o não conhecimento de um recurso ou a extinção de um processo sem resolução do mérito só serão legítimos, então, naqueles excepcionais casos em que se encontre vício verdadeiramente insanável ou que, havendo necessidade de atividade da parte para que seja sanado o vício, esta permaneça inerte e não o corrija, inviabilizando a superação do obstáculo.

Percebe-se a presença do princípio da primazia do mérito não só no artigo $4^{\circ}$, mas também nos dispositivos normativos que tratam do aprimoramento dos filtros recursais e da forma como o Poder Judiciário deve colaborar para que o mérito do processo seja enfrentado ao analisar os requisitos de admissibilidade dos recursos, a exemplo dos artigos 932, parágrafo único; 1.007, $\S 2^{\circ}$ e $4^{\mathrm{o}} ; 1.029, \S 3^{\mathrm{o}} ; 1.032$ e 1.033 do Código de Processo Civil.

Desse modo, pode-se constatar que não basta aumentar os filtros recursais, é preciso aprimorá-los e compatibilizá-los com os direitos fundamentais, para que o sistema de garantias processuais seja preservado.

\section{O DIREITO FUNDAMENTAL DE ACESSO À JUSTIÇA}


A Constituição de 1988 garante a todos o acesso à justiça, direito fundamental através do qual é possível buscar a concretização do demais direitos pelo Poder Judiciário.

$\mathrm{O}$ acesso não é somente à justiça enquanto Poder Judiciário, mas, também, o direito de receber uma tutela estatal adequada e justa, seja ela qual for, vale dizer, independente do resultado.

Nas lições de WATANABE $(1988,128)$ :

\begin{abstract}
Não se trata apenas de possibilitar o acesso à Justiça, enquanto instituição estatal, e sim de viabilizar o acesso à ordem jurídica justa. Uma empreitada assim ambiciosa requer, antes de mais nada, uma nova postura mental. Deve-se pensar na ordem jurídica e nas respectivas instituições, pela perspectiva do consumidor, ou seja, do destinatário das normas jurídicas, que é o povo, de sorte que o acesso à Justiça traz à tona não apenas um programa de reforma como também um método de pensamento, como com acerto acentua Mauro Capelletti.
\end{abstract}

Como se vê, além do acesso formal à justiça, assegurado pela Constituição de 1988, há o acesso material, tão importante quanto, pois se espera um adequado pronunciamento do Poder Judiciário quando procurado pelo jurisdicionado, em prol da segurança jurídica no processo e do apaziguamento das relações sociais (MARINONI; MITIDIERO: 2017, 28).

Na verdade, trata-se de uma norma jurídica bastante complexa, apesar de a expressão “acesso à justiça” remeter a um significado linguístico fácil de perceber, ao menos superficialmente (CAPELLETTI; GARTH: 1988, 8). Com efeito, o acesso à justiça envolve questões econômicas, sociais e culturais "resultantes de processos de socialização e de interiorização de valores dominantes muito difíceis de transformar." (SANTOS: 1993, 114).

\title{
3.1. O sistema de garantias processuais
}

A Constituição Federal, em seu artigo $5^{\circ}$, determina que procedimentos devem ser observados quando está em jogo a esfera patrimonial do particular (inciso XXIV), assegura o direito de participação nas questões que integram os espaços públicos de interação social (inciso XXVI, "a"), também zela pela transparência, com o direito de todos receberem informações dos órgãos públicos (inciso XXXIII), de peticionar perante as esferas do poder 
público (inciso XXXIV, “a”). Garante o amplo acesso ao judiciário (inciso XXXV) e a plenitude de defesa no júri (inciso XXXV). Além disso, a Constituição pró́be qualquer tipo de prática atentatória dos direitos e liberdades fundamentais (inciso XLI) e que toda a penalidade - inclusive a multa - deve ser devidamente regulamentada por lei (inciso XLVI). A Carta Suprema assegura que ninguém será processado nem receberá sentença por autoridade que não seja competente (inciso LIII) e tampouco privado de seus bens sem o devido processo legal (inciso LIV). Ademais, assegura a publicidade dos atos processuais (inciso LX) e garante a todos uma razoável duração do processo (inciso LXXVIII).

Pode-se perceber, deste arquétipo constitucional, que ordenamento jurídico brasileiro proporcionará para todas as pessoas um mínimo de previsibilidade, que os procedimentos sejam quais forem - terão um tratamento específico, de modo a não causar surpresa para ninguém e que qualquer imposição ao particular será precedida de um rito previamente determinado e que a duração do processo não ficará aquém nem além do esperado.

Como se vê, não se pode falar em direito fundamental de acesso à justiça sem analisar o processo civil enquanto sistema de garantias, pois o direito processual possibilita a função jurisdicional "através de um sistema de garantias processuais que viabiliza a tutela judicial efetiva através do devido processo substantivo" (NAVARRETE: 2003, 535).

Sendo assim, é o conjunto de garantias processuais que viabiliza a concretização do compromisso constitucional de proporcionar a todos os integrantes da sociedade brasileira o acesso à justiça. Com efeito, o processo assegura e protege o tráfego dos bens litigiosos, sendo o acesso à justiça a porta de entrada para que todas as pessoas possam obter a tutela efetiva dos juízes e dos Tribunais, inclusive os Superiores, favorável ou não.

Desse modo, o Estado tem o dever de assegurar a todos, desde o mais humilde cidadão à mais poderosa pessoa - física ou jurídica - o acesso à justiça, entregando uma tutela judicial efetiva.

O acesso à justiça deve ser oportunizado a todos, em todas as instâncias. Portanto, o jurisdicionado que apresentar o seu recurso de maneira apropriada merece obter pronunciamento, também adequado, dos Tribunais.

No contexto, a jurisprudência defensiva, quando aplicada de maneira automática e mecanizada, não se encaixa no compromisso constitucional de prestação jurisdicional que contempla um verdadeiro sistema de garantias processuais. 


\subsection{Consequências da jurisprudência defensiva}

Não há espaço, na cultura jurídica contemporânea, para decisões judiciais refratárias que bloqueiam o acesso à justiça.

Em tempos de pós-modernidade, em que a transparência nas relações humanas é cada vez mais valorizada, ainda que a forma seja importante para organizar o processo, o formalismo não pode ser um "subterfúgio para não admitir o regular processamento de recurso, obstando que o instrumento atinja sua finalidade essencial" (OLIVEIRA: 2006, p. 26). O mundo não tolera mais a primazia pelas aparências, as negociações políticas não são mais secretas (STEVEN \& ZIBLATT: 2018, 45), as informações estão pulverizadas, a autoridade dos poderes está enfraquecida (VIEIRA: 2018, 148), o cidadão comum sabe melhor de direitos e obrigações e tem a noção de que a força da dinâmica dos grupos de pressão, do modo como está, talvez, não se mantenha no futuro.

A transparência está em sintonia com a ideia de Estado Democrático de Direito, conforme pontua ÁVILA $(2011,215)$ :

\footnotetext{
Ainda, o princípio democrático, ao exigir a participação dos cidadãos na formação e na condução das políticas públicas, funciona como elemento garantidor de transparência estatal: só há efetiva participação cidadã no controle das atividades estatais quando há transparência com relação a resultados, a processos, a conteúdos e a responsabilidades.
}

Percebe-se, também, um movimento no pensamento coletivo da sociedade brasileira de valorização crescente pela ideia da acessibilidade, de modo geral. O contexto atual mostra que o inacessível, seja ele qual for, dia após dia, se enfraquece e perde seu valor, ao passo que a transparência é enaltecida. Nesta conjuntura, o Estado, acompanhando esta dinâmica, deve otimizar a transparência, a fundamentação e o cuidado com os direitos fundamentais e com as garantias processuais, encontrando caminhos de adaptação, mexendo em suas estruturas, se preciso for.

Até mesmo porque, caso assim não fizer, a frequente agressão ao direito fundamental à justiça através da aplicação mecanizada da jurisprudência defensiva vai acarretar outras consequências. Dito de outro modo: o problema seguirá, ainda que transferido para outro lugar. 


\subsection{A Ação Rescisória}

O conflito entre o compromisso constitucional com o sistema de garantias processuais e a sobrecarga do Poder Judiciário abre espaço para a utilização da ação rescisória como resposta ao efeito deletério da jurisprudência defensiva e como alternativa para a realização do direito fundamental do acesso à justiça.

Quando a jurisprudência defensiva é realizada de forma automática, as chances de deixar passar questões importantes postas à apreciação do Poder Judiciário são enormes. Quando isso acontece, há somente um verniz de do devido processo substantivo: é um número a menos no acervo.

Decidir sem tutelar - o que muitas vezes ocorre na aplicação mecanizada da jurisprudência defensiva - "não é o que se espera do processo civil no Estado constitucional." (MARINONI; ARENHART: 2007, 56)

A batida apressada do carimbo da não apreciação do mérito no processo judicial, acaba abandonando um direito que foi efetivamente violado e está ali, presente nos autos, esperando ser reintegrado, recuperado, reestabilizado.

Verdadeira a constatação do Ministro GILMAR MENDES no julgamento do AgR no AI 496136:

Sabemos que o indeferimento de muitos desses recursos extraordinários, especialmente nessa quadra de recursos de massa, acaba dando ensejo à discussão e à propositura, agora, de inúmeras ações rescisórias.

Apropriado, também, transcrever a averiguação de MACHADO SEGUNDO (2016, 516):

(...) Foi justamente a irracionalidade no exame do atendimento dos pressupostos recursais que levou as Cortes Superiores a não conhecerem de inúmeros recursos interpostos contra decisões que contrariavam sua jurisprudência dominante, fazendo com que transitasse em julgado. E foi precisamente o inconformismo legítimo das partes que se viram vítimas de um trânsito em julgado divergente da jurisprudência dominante a respeito do assunto que as levou a rediscutir a questão em sede de rescisória. 
Desse modo, a obstrução ao direito fundamental de acesso à justiça na aplicação da jurisprudência defensiva leva o jurisdicionado a utilizar a ação rescisória, que acaba se revelando a via adequada para fazer valer a eficácia do direito ao amplo acesso ao Poder Judiciário, assim como à realização do sistema de garantais processuais como um todo.

De acordo com esta perspectiva, a ação rescisória é o meio de resgatar as raízes do processo, que foi “concebido para 'dar' direitos a quem os tem” (WAMBIER: 2001, 1091). Com efeito, decisões judiciais refratárias, preocupadas mais em desafogar o congestionamento enfrentado pelo Poder Judiciário do que identificar os problemas jurídicos e buscar a solução apropriada para eles, se desconectam da genealogia do processo e do dever do Estado de efetivar os direitos fundamentais, pois não é possível, a pretexto de otimizar o tráfego avassalador dos processos judiciais, restringir a realização do direito fundamental de acesso à justiça.

Além de se distanciar do propósito do processo, a jurisprudência defensiva - muitas vezes - não desafoga o Poder Judiciário. Pelo contrário. Faz brotar incontáveis proposituras de ações judicias para rescindir as patologias jurídicas que ocorreram ou foram ocorrendo ao longo do processo originário e não foram reconhecidas, capturadas e removidas pelo assoberbado Poder Judiciário.

A apressada jurisprudência defensiva é capaz de subverter até mesmo as características da ação rescisória, pensada como um instrumento excepcional, cujas hipóteses de cabimento são limitadas pela regra processual que a contempla. O excessivo e desmedido bloqueio ao acesso à jurisdição pelas decisões defensivas faz emergir as hipóteses da ação rescisória que, caso proliferada, perderá seu traço peculiar que é ser um instrumento raro.

\section{CONCLUSÃO}

Assim, constata-se que a jurisprudência defensiva é um dado real na cultura jurídica dos Tribunais, notadamente os Superiores, que precisam resolver o problema do número avassalador de recursos.

Ocorre que o acesso à justiça é um direito fundamental conquistado com muita luta pela sociedade brasileira e garantido pelo Estado Democrático de Direito, que assegura a 
todos o recebimento de uma prestação jurisdicional atenta, sensível aos direitos fundamentais, engajada na identificação dos problemas jurídicos e na busca das melhores soluções para eles.

Desse modo, a aplicação mecanizada e automática da jurisprudência defensiva vai contra o espírito do processo civil no Estado constitucional, pois as chances de restringir o acesso à justiça de maneira não autorizada pela Constituição Federal de 1988 são enormes. Caso isso aconteça, a ação rescisória será a possibilidade de realização deste tão relevante direito que, na verdade, é a porta de entrada para realização de todos os demais direitos fundamentais.

A compreensão de que a ação rescisória é a resposta ao efeito deletério da aplicação instantânea da jurisprudência defensiva mostra a potencialidade da ação rescisória de funcionar como um importante instrumento de proteção judicial para afastar a obstrução do acesso ao Poder Judiciário desencadeada pelas decisões que se negam a analisar o mérito das questões jurídicas postas à sua apreciação, tendo em vista que o compromisso constitucional com as garantias processuais determina que todos os meios necessários devem ser empregados para que a justiça seja, de verdade, acessível para todos.

Portanto, conclui-se que o direito fundamental à justiça não pode ser sacrificado em nome da tentativa de diminuição do congestionamento de processos no Poder Judiciário e, ainda mais, que a aplicação desenfreada da jurisprudência defensiva não resolve a sobrecarga de processos judiciais. Tão somente desloca o problema, exigindo do jurisdicionado um fôlego heroico para buscar fazer valer os seus direitos pela via da ação rescisória e não trazendo, para o Poder Judiciário, a tão desejada diminuição do número de processos.

\section{REFERÊNCIAS BIBLIOGRÁFICAS}

ALEXY, Robert. Teoria dos direitos fundamentais. 2ed. São Paulo: Malheiros, 2011. Tradução de Virgílio Afonso da Silva.

ÁVILA, Humberto. Segurança Jurídica: entre permanência, mudança e realização no Direito Tributário. São Paulo: Malheiros, 2011.

O que é "devido processo legal"? In: Teoria do Processo: panorama doutrinário mundial. DIDIER Jr., Fredie (org). v. 2. Bahia: JusPodvum, 2010, p. 353-362.

BRASIL. Superior Tribunal de Justiça. EAREsp n. ${ }^{\circ}$ 746775. Relator: Ministro João Otávio Noronha Relator para o acórdão Ministro Luis Felipe Salomão. Brasília, DF, 19 de julho de 2018. Brasília. 
BRASIL. Superior Tribunal de Justiça. AgInt no AREsp n. ${ }^{\circ}$ 957821. Relator: Ministro Raul Araújo Relator para o acórdão Ministra Nancy Andrighi. Brasília, DF, 20 de novembro de 2017.

BRASIL. Superior Tribunal de Justiça. REsp n. ${ }^{\circ}$ 682932. Relator: Ministro Moura Ribeiro. Brasília, DF, 19 de abril de 2017.

BRASIL. Superior Tribunal de Justiça. EDcl nos EDcl nos EDcl no EREsp n. 839473. Relator: Ministro Napoleão Nunes Maia Filho Relatora para o acórdão Ministra Regina Helena Costa. Brasília, DF, 01 de dezembro de 2015.

BRASIL. Superior Tribunal de Justiça. AgRg no Ag n. ${ }^{\circ}$ 902614. Relator: Ministra Denise Arruda. Brasília, DF, 12 de dezembro de 2007.

BRASIL. Supremo Tribunal Federal. RE n. 551476 AgR. Relator: Ministro Menezes de Direito. Brasília, 27 de agosto de 2009.

BRASIL. Supremo Tribunal Federal. AgR no AI n. ${ }^{\circ}$ 496136. Relator: Ministro Celso de Mello. Brasília, 18 de maio de 2004.

CABRAL, Antonio do Passo. Coisa julgada e preclusões dinâmicas: entre continuidade, mudança e transição de posições processuais estáveis. Salvador: JusPodivm, 2013.

CÂMARA, Alexandre Freitas. O Princípio da Primazia da Resolução do Mérito e o Novo Código de Processo Civil. Emerj, Rio de Janeiro, v. 18, n. 70, p. 42-50, set-out/2015.

CAPPELLETTI, Mauro; GARTH, Bryant. Acesso à justiça. Trad: NORTHFLEET, Ellen Gracie. Porto Alegre: Fabris, 1988.

Conselho nacional de justiça. Justiça em números. 2020. Disponível em: https://www.cnj.jus.br/wp-content/uploads/2020/08/WEB-V3-Justi\%C3\%A7a-em-

N\%C3\%BAmeros-2020-atualizado-em-25-08-2020.pdf. Acesso em: 04 abr. 2021.

COUTO, Monica Bonetti. O novo CPC e a (esperança de) superação da jurisprudência defensiva. Revista Eletrônica de Direito Processual. Rio de Janeiro. Ano 12, v. 19, n. ${ }^{\mathbf{0}} 3$. Setembro a Dezembro de 2018, p. 543-564.

ENGISCH, Karl. Introdução ao pensamento jurídico. 9 ed. Lisboa: Fundação Calouste Gulbenkian, 2004. Tradução de J. Baptista Machado.

FARINA, Fernanda Mercier Querido. Jurisprudência Defensiva e a Função dos Tribunais Superiores. Revista de Processo, São Paulo, v. 209, ano 37, p. 105-144. Julho/2012.

GUASTINI, Riccardo. Trattato di Diritto Civile e Commerciale: interpretare e argomentare. Milano: Dott. A. Giuffrè Editore, 2011. 
GRAU, Eros Roberto. Ensaio e discurso sobre a interpretação/aplicação do direito. 4 ed. São Paulo: Malheiros, 2006.

LARENZ, Karl. Metodologia da Ciência do Direito. $4^{\mathrm{a}}$ ed. Lisboa: Fundação Calouste Gulbenkian, 2005. Tradução de José Lamego.

LUCENA FILHO, Humberto de Lima. A Cultura da Litigância e o Poder Judiciário: noções sobre as práticas demandistas a partir da justiça brasileira. Disponível em: http://www.publicadireito.com.br/artigos/?cod=84117275be999ff5. Acesso em: 04 abr. 2021.

MACHADO SEGUNDO, Hugo de Brito. Os recursos no Novo CPC e a "Jurisprudência Defensiva. DIDIER Jr. Freddie (coord.) MACÊDO, lucas Buril de; PEIXOTO, Ravi, FREIRE, Alexandre (org.) Processo nos Tribunais e Meios de Impugnação às Decisões Judiciais. JusPodivm, 2ed. 2016.

MAcCORMICK. Argumentação jurídica e teoria do direito. Tradução de Waldéa Barcellos. São Paulo: Martins Fontes, 2006.

MARINONI, Luiz Guilherme; MITIDIERO, Daniel. Ação Rescisória: Do Juízo Rescindente ao Juízo Rescisório. São Paulo: Revista dos Tribunais, 2017, p. 28.

MARINONI, Luiz Guilherme. ARENHART, Sérgio Cruz. Execução. São Paulo: Revista dos Tribunais, 2007.

NAVARRETE, Antonio María Lorca. El Derecho Procesal como Sistema de Garantías. Boletín Mexicano de Derecho Comparado, nueva serie. Año XXXVI, núm. 107, mayoagosto de 2003, p. 531-557.

MONEBHURRN, Nitish. Como preparar uma tese de doutorado. Da escrita à defesa: um relato a partir da experiência dos Professores. Rio de Janeiro: Processo, 2020.

OLIVEIRA, Carlos Alberto Alvaro. O formalismo-valorativo no confronto com o formalismo excessivo. Revista da Faculdade de Direito da UFRGS, n. ${ }^{\circ}$ 26, 2006.

OLIVEIRA, Pedro Miranda de. Seção II. Do recurso extraordinário e do recurso especial. Subseção I. Das disposições gerais. In: WAMBIER, Teresa Arruda Alvim; DIDIER JR., Fredie; DANTAS, Bruno; TALAMIN, Eduardo (coord.) Breves comentários ao novo Código de Processo Civil. São Paulo: Revista dos Tribunais, 2015, p. 2297-2298.

SARLET, Ingo Wolfgang. A eficácia dos direitos fundamentais: uma teoria geral dos direitos fundamentais na perspectiva constitucional. 11 ed. Porto Alegre: Livraria do Advogado, 2012.

SANTOS, Boaventura de Sousa. Introdução à sociologia da administração da justiça. In: Introdução à sociologia da administração da justiça. In: SOUSA JUNIOR, José Geraldo de; AGUIAR, Roberto A. R. de. Introdução crítica ao direito do trabalho. Brasília: Universidade de Brasília; CEAD/NEP, 1993. 
STEVEN, Levitsky \& ZIBLATT, Daniel. Como as democracias morrem. Trad: AGUIAR, Renato. 1 ed. Rio de Janeiro: Zahar, 2018.

VAUGHN, Gustavo Fávero. A Jurisprudência Defensiva no STJ à Luz dos Princípios do Acesso à Justiça e da Celeridade Processual. Revista de Processo. Ano 41, vol. 254, abril/2016, WAMBIER, Teresa Arruda Alvim (Coord.) São Paulo: Revista dos Tribunais, p. 340-373.

VIEIRA, Oscar Vilhena. A batalha dos poderes: Da transição democrática ao mal-estar constitucional. $1^{\text {a }}$ ed. São Paulo: Companhia das Letras, 2018

WAMBIER, Teresa Arruda Alvim. Repercussão Geral. Revista do Instituto dos Advogados de São Paulo. São Paulo: Revista dos Tribunais, v. 19, janeiro/2007.

WAMBIER, Teresa Arruda Alvim. Fungibilidade dos meios: uma outra dimensão do princípio da fungibilidade. São Paulo: Revista dos Tribunais, 2001, p. 1091.

WATANABE, Kazuo. Acesso à Justiça e sociedade moderna. Participação e processo. São Paulo: Revista dos Tribunais, 1988, p. 128. 